\title{
An Empirical Research on Evaluation of Low-Carbon Economy in Guangdong Province, China: Based on "Production, Life and Environment"
}

\author{
Chunrong Liu1*, Yaoqiu Kuang2, Ningsheng Huang2, Xiuming Liu3 \\ ${ }^{1}$ Jiaying University, Meizhou, China \\ ${ }^{2}$ Sustainable Development Research Center, Guangzhou Institute of Geochemistry, Chinese Academy of \\ Sciences, Guangzhou, China \\ ${ }^{3}$ School of Humanities and Social Science, Guangzhou Civil Aviation College, Guangzhou, China \\ Email: ${ }^{\text {Ichrok@163.com }}$
}

Received 2 September 2014; revised 2 October 2014; accepted 1 November 2014

Copyright (C) 2014 by authors and Scientific Research Publishing Inc.

This work is licensed under the Creative Commons Attribution International License (CC BY).

http://creativecommons.org/licenses/by/4.0/

(c) (i) Open Access

\begin{abstract}
In order to promote the development of Low-carbon economy (LCE), it is important to establish a scientific LCE quantitative evaluation system. Based on the concept of "life, production and environment", this paper builds the decomposition models of carbon emission influencing factors from these three aspects and inductively analyzes the factors influencing LCE development. According to these factors, this paper correspondingly builds a quantitative evaluation index system of LCE, which makes up the deficiency in selection index in theory. The evaluation of LCE in Guangdong Province is carried out by applying the analytic hierarchy process, entropy method and composite index method. Results showed that the development of LCE in Guangdong was on the decline during the period of 2000-2012 and the rapid economic growth in Guangdong was achieved at the expense of the environment. Therefore, this paper puts forward some suggestions that Guangdong should improve the utilization of clean energy, pay attention to the optimization of energy mix from household and productive sector, and attach equal importance to the structure optimization when enlarging its foreign trade scale. In addition, with limited land resources, Guangdong should take into account the common development of production, life and environment in land planning.
\end{abstract}

\section{Keywords}

Carbon Emission, Low-Carbon Economy, Quantitative Evaluation

\footnotetext{
${ }^{*}$ Corresponding author.
}

How to cite this paper: Liu, C.R., Kuang, Y.Q., Huang, N.S. and Liu, X.M. (2014) An Empirical Research on Evaluation of Low-Carbon Economy in Guangdong Province, China: Based on "Production, Life and Environment". Low Carbon Economy, 5, 139-152. http://dx.doi.org/10.4236/Ice.2014.54015 


\section{Introduction}

The carbon cycle is an important mechanism to maintain ecological balance. Before the industrial revolution, the carbon cycle was basically balanced in ecosystem. Since the industrial revolution, human activity had broken the original carbon balance in ecosystem, causing a series of global problems such as climate warming, relative rise of sea level, extreme weather, and so on. A systemic risk happened to the environmental resources of the global system. So, the international community has carried out positive response. In that context, to develop Low-carbon economy (LCE) is put forward. LCE is a way to realize sustainable economic development. Since this concept was introduced in the Energy White Paper 2003 by the UK government, study on LCE has been continuous in these years and becomes a hot topic. As a branch of LCE research, research on LCE evaluation is still in the stage of exploration and development. Some representative researches are as follows: under the circumstances of the world's LCE development, Qin [1] analyzed the relations between the development of LCE and technology reform, built the technology reform project evaluation index system from the angle of the enterprise technical reform and innovation based on LCE theory, and evaluated technical reform project by applying fuzzy multi objective comprehensive evaluation model. Hong and Chen [2] argued that the evaluation of LCE development could provide reliable information support for the regional decision-making. They obtained relevant data with satellite remote sensing imageries as support, and constructed the evaluation index of low carbon development in Fujian Province, China. Hu [3] et al. summarized 30-year successful experience in energy efficiency in China. Regarding that as the core of experience information for LCE development, they evaluated China's LCE development in an Economy-Energy-Electricity-Environment framework. In addition, some other research institutions and individuals conducted exploratory studies on the evaluation of LCE development [4]-[11]. The previous researches have different characteristics but also some limitations: First, index selection is mostly based on the understanding of the concept of LCE, lack of convincing theoretical basis. Second, most of index systems have too broad focuses, not targeted, and the definition and measurement of some indexes are very vague, such as "low-carbon concept of residents", "low-carbon consumption concept". It is difficult to measure and evaluate objectively. Some other indexes, on the other hand, have too narrow focuses. Third, some studies do not take the sample size into account when selecting evaluation method and the conclusions from them tend to lose statistical significance.

In fact, it is greatly significant to select the evaluation indexes suitable for a region or a country and build a set of scientific and feasible LCE evaluation index system. Therefore, based on the existing research results, this paper attempts to build the decomposition models of carbon emission influencing factors from three aspects of "production, life and environment" with the concept of common development of production, life and environment as the starting point, and to find out the major factors that influence the LCE development, which provides a reasonable basis for the construction of LCE development index system. Meanwhile, this paper makes a quantitative evaluation of LCE development in Guangdong Province using this evaluation system, and puts forward some suggestions to promote it.

Guangdong Province, located in the subtropical part of southern China mainland, between latitude $20^{\circ} 13^{\prime} \mathrm{N}$ $25^{\circ} 31^{\prime} \mathrm{N}$ and longitude $109^{\circ} 39^{\prime} \mathrm{E}-117^{\circ} 19^{\prime} \mathrm{E}$, is one of the regions whose economy have achieved rapid development since reform and opening up in 1978. Guangdong Province's Gross Domestic Product (GDP) and urbanization rate reached 62163.97 billion Yuan (current price) and 67.76\% in 2013, respectively. Actually, Guangdong Province’s GDP, Industrialization Process, urbanization level and export-oriented degree all ranks forward in China. This indicates that Guangdong Province is one of the biggest provinces in economy in China. There are nine major industries, including electronic and information technology, electric equipment and special-purpose machinery, petroleum and chemistry, textile and garments, food and beverage, building materials, logging and papermaking, medicine, motor vehicle. Energy is the main driving force of economic development. The rapid economic development brought about huge amount of energy consumption and carbon emissions in Guangdong Province, so Guangdong Province has inevitably become one of the largest regions in terms of energy consumption and carbon emissions in China, and is facing greater pressure to reduce emissions. Therefore, Developing LCE is the necessary choice to Guangdong Province.

\section{Methods and Data Resources}

\subsection{Calculation of Carbon Emissions}

There are actually two methods of calculating carbon emissions. The first is to consider only carbon emissions 
from human activities. That is, consider only the narrow carbon sources not natural emission sources (such as soil respiration). At present, Intergovernmental Panel on Climate Change (IPCC) adopts this method [12]. The other is to analyze all emission sources in ecosystem with ecosystem as the research object. That is, consider not only the carbon emissions from energy consumption in human activities, but also the natural emission sources (especially human land-use change factors). Therefore, all carbon dioxide emission sources in ecosystem include human production activities (such as industrial production), daily life activities (such as the burning of fossil fuels) and natural systems (such as soil respiration). As for the natural carbon emissions, considering the focus of research, this paper just takes soil respiration into account, and that will not affect the conclusion. Therefore, calculations of carbon emissions in this research include two parts: carbon emissions from energy consumption and carbon emissions from soil respiration.

With the method recommended by IPCC as reference, the formula for the calculation of carbon emissions from energy consumption is:

$$
C=\sum_{i} \sum_{j} C_{i j}=\sum_{i} \sum_{j} E_{i j} \times f_{j}
$$

where $C$ is carbon emission from energy consumption, $i$ is the type of industry, $j$ is the type of energy, $C_{i j}$ represents carbon emissions of energy $j$ in industry $i, E_{i j}$ represents consumption of energy $j$ in industry $i$, and $f_{j}$ is carbon emission coefficient of energy $j$. Carbon emission coefficients of different kinds of energy adopts the data released by IPCC [13].

Carbon emissions from soil respiration are calculated according to the land use classification. Consulting land use classification system according to "Chinese Land Classification", this paper divides the land use types into 3 categories of Class-A: agricultural land, construction land and land unused. With reference to the calculation method of carbon emissions from soil respiration by Xiao Chujuan, Kuang Yaoqiu et al. [14] and Kuang Yaoqiu et al. [15], the formula is:

The carbon emission from soil respiration is the average soil respiration velocity multiplied by the total area of various vegetation types.

All kinds of soil, according to vegetation types, are subdivided into arable soil, forest soil, woodland shrub soil, orchard soil, grassland soil, and so on. The average soil respiration velocity is shown in Table 1. It is generally believed that the root respiration of plants accounts for $30 \%-60 \%$ of a total soil respiration. Combined with the real situation of Guangdong, the ratio of forest root respiration is $45 \%$ of total soil respiration and the ratio of grassland root respiration is 35\% [15]. Because the corresponding carbon emissions from the root respiration of plants have been included in respiratory consumption in the plant community, they should be deducted in the calculation of carbon emissions here. This paper only focuses on the carbon emissions of farmland, garden plot, woodland, grassland and land unused.

\subsection{Decomposition of the Factors Affecting Carbon Emissions}

Professor Ye Wen-hu in Peking University put forward "the common development of life, production and environment" as the criterion of social construction at the seventh China Forum on Environment and Development in 2011. The highlight of the criterion is not only to ask for a common improvement and development of life, production and environment, but also to achieve a win-win situation between them in time and space [16]. And several other researchers in China are agreeing with Professor Ye. The author believes that sustainable economic development means the common development of life, production and environment, and LCE is a way to realize sustainable economic development. So, the author argues that LCE development can also be considered from life, production and environment. The core of LCE development is to consider developing the socioeconomic and controlling the discharge of such greenhouse gas as carbon dioxide into the atmosphere in human activities at the same time. But how to control it? It can be considered from the control of carbon emissions in production, life and environment. In life and production, consider controlling carbon emissions from energy consumption; and in environment, consider that human activities will change the mode of land use. For example, in

Table 1. The average respiration velocity of soil and water $t \cdot \mathrm{hm}^{2} \cdot \mathrm{a}^{-1}[15]$.

\begin{tabular}{cccccccc}
\hline Arable soil & Forest soil & Woodland shrub soil & Orchard soil & Green land soil & Grassland soil & Non-forest land & Lakes \\
\hline 5.44 & 6.47 & 5.67 & 6.62 & 6.65 & 4.7 & 2.24 \\
\hline
\end{tabular}


the process of urbanization a large increase of the construction land results in a big decline in land vegetation, which will affect the soil organic carbon storage and the carbon balance of natural ecological system. Therefore, research on LCE development can be conducted based on production, life and environment. It's necessary to analyze the factors influencing LCE development from the three aspects. This paper presents in detail the decomposition of carbon emission influencing factors from the perspective of energy consumption and soil respiration, as well as the factors influencing LCE development induced from the decomposition model. Carbon emission influencing factors from energy consumption are mainly focused on production and life while those from soil respiration on environment. And Carbon emissions decomposition model is constructed according to the real situation of Guangdong Province, which is the extension of Kaya's [17] identical equation. Kaya's identical equation is:

$$
\mathrm{CO}_{2}=\frac{\mathrm{CO}_{2}}{E} \cdot \frac{E}{\mathrm{GDP}} \cdot \frac{\mathrm{GDP}}{P} \cdot P
$$

In this identical equation, $\mathrm{CO}_{2}, E$, GDP and $P$ stand for emission of $\mathrm{CO}_{2}$, total energy consumption, gross domestic product and total domestic population respectively. According to the decomposition method of this study, there is the following equation:

$$
C=C_{1}+C_{2}+C_{3}
$$

$C, C_{1}, C_{2}$ and $C_{3}$ stand for total carbon emissions, energy-related carbon emissions from productive sector, energy-related carbon emissions from household sector and carbon emissions from soil respiration.

The following is how $C_{1}, C_{2}$ and $C_{3}$ are extended and innovated based on Kaya's identical equation.

1) Model for decomposition of factors affecting energy-related carbon emissions from production sector.

Taking it into account that the industrial structure is an important factor that influences carbon emissions, and since Guangdong Province is in the urbanization development, which is China's door for foreign trade with distinctive characteristics of the export-oriented economic development, such factors as the industrial structure, urbanization and the specialization in international trade are embodied in the identical equation in this paper. Therefore, $C_{1}$ can be decomposed as follows:

$$
C_{1}=\sum_{i} \sum_{j}\left(\frac{C_{i j}}{P E_{i j}} \cdot \frac{P E_{i j}}{P E_{i}} \cdot \frac{P E_{i}}{\mathrm{GDP}_{i}} \cdot \frac{\mathrm{GDP}_{i}}{\mathrm{GDP}} \cdot \frac{\mathrm{GDP}}{\mathrm{NX}} \cdot \frac{\mathrm{NX}}{P} \cdot \frac{P}{P_{u}} \cdot \frac{P_{u}}{S_{u}} \cdot \frac{S_{u}}{S} \cdot \frac{S}{\mathrm{GDP}} \cdot \mathrm{GDP}\right)
$$

In this equation, $i$ stands for type of industry-primary industry, secondary industry and tertiary industry respectively. $j$ stands for type of energy. So $C_{i j}$ means carbon emissions of energy $j$ in industry $i . P E_{i j}$ means consumption of energy $j$ in industry $i . P E_{i}$ means energy consumption in industry $i$. GDP means gross domestic product while $\mathrm{GDP}_{i}$ means the value added of industry $i$ in GDP. NX means net exports. $P$ means permanent resident population and $\mathrm{S}$ means the total territory.

$\frac{C_{i j}}{P E_{i j}}$ means carbon emissions from per unit production of different type energy, i.e. carbon emission coefficient. $\frac{P E_{i j}}{P E_{i}}$ means energy consumption proportion of energy $j$ in industry $i$, i.e. energy structure. $\frac{P E_{i}}{\mathrm{GDP}_{i}}$ means energy consumption per GDP of industry $i$, i.e. energy intensity of industry $i . \frac{\mathrm{GDP}_{i}}{\mathrm{GDP}}$ means the GDP proportion of industry $i$ in total GDP, i.e. industry structure. $\frac{\mathrm{GDP}}{\mathrm{NX}}$ is the reciprocal of net export's proportion in GDP and $\frac{\mathrm{NX}}{P}$ means net export per capita, which both show the influence of specialization in international trade on carbon emissions. $\frac{P}{P_{u}}$ means the reciprocal of population urbanization, $\frac{P_{u}}{S_{u}}$ means population density of built-up area, and $\frac{S_{u}}{S}$ means land urbanization, which show the influence of urbanization 
on carbon emission. $\frac{S}{\mathrm{GDP}}$ is the reciprocal of economic output density.

2) Model for decomposition of factors affecting household energy-related carbon emissions.

Based on Kaya's identical equation, this paper decomposes the carbon emissions from daily life energy consumption as follows:

$$
C_{2}=\sum_{j}\left(\frac{C_{j}}{E_{j}} \cdot \frac{E_{j}}{E} \cdot \frac{E}{P} \cdot P\right)
$$

where $E$ is the household energy consumption, $E_{j}$ is the household energy consumption of energy $j . C_{j}$ is carbon emissions from energy $j . P$ is population size.

$\frac{C_{j}}{E_{j}}$ means carbon emissions from per unit production of different energy, i.e. carbon emission coefficient. $\frac{E_{j}}{E}$ means proportion of energy $j$ in daily life consumption, i.e. energy structure. $\frac{E}{P}$ means daily life energy consumption per capita. $P$ stands for permanent resident population end of year.

3) Model for decomposition of factors affecting carbon emissions from soil respiration.

Considering the influence of change of land use on carbon emissions, this paper decomposes $C_{3}$ influencing factors as follows:

$$
C_{3}=\sum_{g}\left(\frac{C_{g}}{S_{g}} \cdot \frac{S_{g}}{S} \cdot S\right)
$$

where $g$ is type of land use $(g=3) . C_{g}$ is carbon emissions from land use type $g . S_{g}$ means the area of land use type $g . S$ means the total territory.

$\frac{C_{g}}{S_{g}}$ means carbon emissions from per unit area of different land use type, i.e. carbon emission density. $\frac{S_{g}}{S}$ means proportion of different land use type in total territory. $S$ means the total territory.

According to the models-Equations (4)-(6), the factors influencing carbon emissions are energy structure, energy intensity, industry structure, specialization in international trade, urbanization level, economic development, daily life energy consumption structure, daily life energy consumption per capita, population size, carbon emission density, proportion of different land use type in total territory and land area. These models also contain carbon emission coefficient, but it doesn't influence carbon emissions because the carbon emission factor of various kinds of energy is considered constant in practical application. This conclusion is similar to those drawn by Zhaohua Wang et al. [18], Rosa Duarte et al. [19], Fredrik N.G. Andersson, and Peter Karpestam [20]. Factors influencing LCE development can be summed up on the basis of Equations (4)-(6), and shown in Figure 1.

\subsection{LCE Evaluation Index System}

\subsubsection{Index Selection and the Framework Construction of Index System}

1) The Basic Principles of Setting the Index

The construction of index system should follow scientific and system principle, concise and to the point principle, feasibility and representative principle as well as principle of territory.

2) Index Selection

Based on the factors influencing LCE development, LCE evaluation index system is divided into three levels, namely the target layer, factor layer and index layer in this paper. Specific indicators are selected based on the factors influencing LCE development in accordance with doctrine on scientificalness, conciseness, feasibility, representativeness and territoriality.

Here are specifications of some indicators. The "proportion of clean energy consumption" is selected as energy structure indicator in this paper, because there has been great changes in the proportion of clean energy consumption in Guangdong Province since 2000, which can reflect the dynamic changes in energy consumption structure in Guangdong. It is the carbon emission proportion coefficient of the secondary industry, not the carbon emission proportion of the secondary industry, which is selected as industrial structure indicator. The reason 


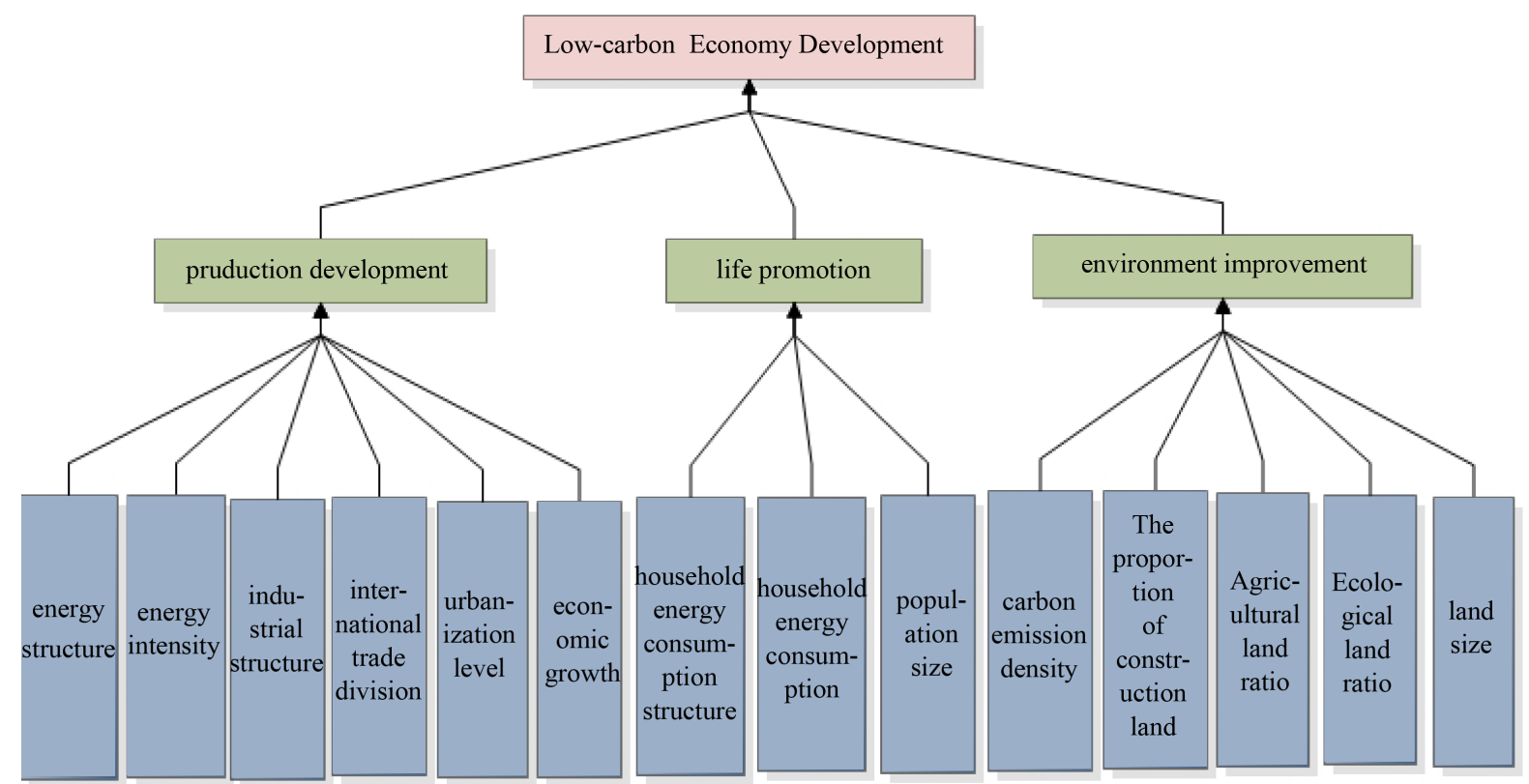

Figure 1. Influencing factors of Low-carbon economy development.

is though the latter is an important structure index of LCE; it has its own limitations. Carbon emission proportion of the secondary industry which is a carbon-intensive industry cannot directly reflect the LCE development. The carbon emission proportion of the secondary industry is high in one area when its output of the second industry takes up large proportion or when its production energy utilization rate is low. On the contrary, the carbon emission proportion of the secondary industry is low in one area when its economy is well developed with an optimized economic structure or when its economy is underdeveloped. As a result, this paper takes carbon emission proportion coefficient of the secondary industry as an indicator based on the real situation of Guangdong Province. In order to reflect the factors influencing the urbanization level, this paper selects the common and representative indicator- "proportion of urban population". In order to reflect the specification in international trade, this paper takes "net export proportion in GDP" as an indicator. This paper also selects "proportion of liquefied petroleum gas consumption" as daily life energy consumption structure indicator, because this kind of energy consumption takes up the largest proportion in all the daily life energy consumption every year. Besides, its carbon emission coefficient is the largest, which is thus the biggest factor influencing the carbon emissions in daily life. There are two indicators concerning land use type including "construction land proportion" and "ecological land proportion". The former represents the biggest negative influence on carbon sequestration while the latter represents the biggest positive influence on carbon sequestration. This paper doesn't take the land area as the ecological low carbon improvement factor indicator. The reason is that this paper studies dynamic changes in LCE development in Guangdong Province over the years, while there have been very small changes in its land area these years, which has little effect on LCE development.

3) The Framework Construction of Index System

The final index system selected is shown in Table 2. Before those indexes are selected, the authors made the correlation test among the indexes under the layers. Results showed that there are not significant correlations between different indexes under three layers all.

4) Explanation of Several Main Indexes

a) Energy Intensity: It means energy consumption/GDP, used to measure energy use efficiency and to reflect the degree of dependence of economy on energy. The energy use efficiency is higher when the energy intensity is lower. It contributes to LCE so it is an index with negative property.

b) Carbon Emission Proportion Coefficient of Secondary Industry: It is the ratio of carbon emission proportion to output value of the secondary industry, used to measure the relations between carbon emission and output in the industry and to reflect low-carbon level of the industrial structure.

c) Proportion of Urban Population: It is the ratio of population living in the town to total resident population. In the process of urbanization, reinforced steel bars, cement and other high energy consumption materials are 
Table 2. Low-carbon economy evaluation index system.

\begin{tabular}{ccclcc}
\hline Target Layer & Factor Layer & No. & \multicolumn{1}{c}{ Index Layer } & Index Property \\
\hline & & $X_{1}$ & Proportion of Clean Energy Consumption (\%) & Positive \\
& $X_{2}$ & Energy Intensity (tons of standard coal/million Yuan) & Negative \\
& Low-Carbon & $X_{3}$ & $\begin{array}{l}\text { Carbon Emission Proportion Coefficient of Secondary } \\
\text { Industry (\%) }\end{array}$ & Negative \\
& Production & $X_{4}$ & Net Export Proportion in GDP (\%) & Negative \\
Lce Evaluation & & $X_{5}$ & Proportion of Urban Population (\%) & Positive \\
Index System & $X_{6}$ & Carbon Productivity (Yuan/tons of carbon) & Positive \\
& Low-Carbon & $X_{7}$ & Liquefied Petroleum Gas Consumption Proportion of & Negative \\
& Life & $X_{8}$ & Daily life Energy Consumption per Capita (kg of standard & Negative \\
& & $X_{9}$ & Toal) & Total Population (million people) & Negative \\
& & $X_{10}$ & Carbon Emission Density (tons of carbon/hectare) & Negative \\
& Low-Carbon & $X_{11}$ & Construction Land Proportion (\%) & Negative \\
& & $X_{12}$ & Ecological Land Proportion (\%) & Positive \\
\hline
\end{tabular}

used in large amount so it restricts LCE. On the other hand, urbanization promotes the efficient and intensive use of resources so it reduces carbon emission per capita. Judging by these two points, the study considers urban population proportion as an index with positive property.

d) Total Population: The study chose permanent resident population end of the year to check the total population. Population increase contributes to more energy consumption, expansion of residential area, construction of roads and railway so that it will change the land use pattern and take up more natural resources. So the increase of total population restricts LCE. It is an index with negative property.

e) Carbon Emission Density: It is the ratio of the net carbon emissions (deducting the carbon sequestration from total carbon emissions from all types of land use) to land area. The total carbon emissions from all types of land use include carbon emissions from construction land, agricultural land and ecological land, of which the calculation of carbon emissions from construction land is mainly focused on carbon emissions from energy consumption, not on carbon emissions from human and animal. And the carbon emissions from agricultural land and ecological land are measured with the carbon emissions from soil respiration. The greater is the index value, the less conducive it is to LCE development. Therefore, it belongs to the negative index.

\subsubsection{Weighting Method}

Methods commonly used are Delphi Method, Analytic Hierarchy Process (AHP), entropy method and principal component analysis method. Considering Delphi Method is too subjective and principal component analysis has the strict request to the sample size, the paper chooses AHP and entropy method. The final weight can be calculated by the combination weighting formula of the subjective and objective weighting methods.

The calculation steps of AHP are as follows:

1) Determine the hierarchy.

2) Build a comparison judgment matrix. In the step, no less than five experts engaged in environmental, resource and economy studies have been invited to judge the relative importance of the various factors by pairwise comparison method and compose matrix. The criterion scale of judgment matrix commonly used " 1 - 9 scale method", which can be show as Table 3.

For guidelines layer contains $n$ indicators, a judgment matrix $A=\left(a_{i j}\right)_{n * n}, a_{i j}>0, a_{i j}=1 / a_{i j}$, can be obtained as follows:

$$
A=\left(\begin{array}{ccc}
a_{11} & \ldots & a_{1 n} \\
\vdots & \ddots & \vdots \\
a_{n 1} & \cdots & a_{n n}
\end{array}\right)
$$


Table 3. Criterion scale: “1 - 9 scale method”.

\begin{tabular}{cc}
\hline Scale levels $a_{i j}$ & Comparison of the two factors \\
\hline 1 & Equal importance \\
3 & Moderate importance \\
5 & Obvious importance \\
7 & Great importance \\
9 & Utmost importance \\
$2,4,6,8$ & Compromise between the above results \\
$1 / a_{i j}$ & $a_{i j}$ is the comparison result $X_{i}$ and $X_{j}, 1 / a_{i j}$ is the comparison result $X_{j}$ and $X_{i}$ \\
\hline
\end{tabular}

Then, the corresponding single-sorted index weights can be calculated according to $A$. The weight of single level sequencing in index layer is represented by $\xi_{i}$, and the single sort weight of factor for the target layer is represented by $\xi_{(0) i}$.

3) Check the consistency of matrix A. Typically, to a judgment matrix of order 3 or more, it is considered as passing the test when the conformance ratio is less than 0.1 . However it isn't considered as passing the test when the conformance ratio is no less than 0.1 , at this time, the comparison judgment matrix should be altered until pass the test.

4) Determine the level of total order $\theta_{i}, \theta_{i}=\xi_{i}+\xi_{(0) i}$.

The calculation steps of entropy method are as follows:

a) Change the index proportion with formula $f_{i j}=\frac{X_{i j}}{\sum_{j=1}^{n} X_{i j}}, \quad(i=1,2,3 \cdots, m ; j=1,2,3 \cdots n ;)$

(Note: In $X_{i j}, i$ is the number of index while $j$ is the number of year).

b) Calculate the index entropy, the entropy of index $i$ can be calculated with formula

$$
g_{i}=-k \sum f_{i j} \operatorname{In} f_{i j} \quad(k=1 / \operatorname{Inn}),
$$

c) Calculate the weight of index $i$ with formula

$$
\omega_{i}=\frac{1-g_{i}}{m-\sum_{i=1}^{m} g_{i}} .
$$

\subsubsection{Comprehensive Evaluation Method}

At present, Methods commonly used are comprehensive index method, TOPSIS and so on. The paper chooses the comprehensive index method.

The analysis steps are as follows:

1) Calculate individual index number of different indicator

The formula is $y_{i j}=\frac{Z_{i j}}{M_{i}}$ (positive index) or $y_{i j}=\frac{M_{i}}{Z_{i j}}$ (negative index). $Z_{i j}$ is the original value, $y_{i j}$ is the indicator index and $M_{i}$ is mean value of $Z_{i}$.

2) Calculate the composite index

The formula is

$$
P_{j}=\sum_{i=1}^{m} y_{i j} \omega_{i} \quad(i=1,2,3, \cdots, m)
$$

where $P_{j}$ means the composite index of corresponding year, $\omega_{i}$ means the corresponding weight of $X_{i}$.

\subsection{Data Sources and Processing}

The energy data used in this paper are quoted from Energy Balance Sheet of Guangdong Province in the China 
Energy Statistics Yearbook (2001-2013). Other basic data used in this article come from Guangdong Province Statistical Yearbook (2001-2013) in China. The data of some index used in the paper are calculated based on statistical data (e.g. when we get the carbon emission proportion of the secondary industry, we can calculate the carbon emission proportion coefficient of it. And we can calculate the carbon productivity and carbon emission density, too.) To get rid of the influence of price changes, we converted the GDP at current price to the GDP at constant price in the year 2000 by using Indices of GDP (IGDP, preceding year $=100$ ). The formula of this transformation is shown as follows:

$$
\operatorname{GDP}_{(2000+i)}=\frac{\mathrm{GDP}_{0} \cdot \operatorname{IGDP}_{(2000+1)} \cdot \operatorname{IGDP}_{(2000+2)} \cdots \cdot \operatorname{IGD}_{(2000+i)}}{10^{2 i}}
$$

where $\mathrm{GDP}_{(2000+i)}$ means the real GDP in year $i$ eliminating the effect of price changes, GDP ${ }_{0}$ means nominal GDP in the base period of 2000.

The index Resident Population at year-end rather than Registered Permanent Residence Population is used as the population scale in urban population proportion index, because population mobility in Guangdong is so big that Resident Population at year-end is more accurate than Registered Permanent Residence Population to reflect the LCE status.

The original data is converted into dimensionless data by the average method. To positive index, formula for the dimensionless processing is $Z_{i j}=X_{i j} / \bar{X}_{j}$, and to negative index the formula is $Z_{i j}=\bar{X}_{j} / X_{i j}$. Where $Z_{i j}$ is a dimensionless data, $X_{i j}$ is an original data.

\section{Results}

\subsection{Results of Carbon Emissions}

Considering that the agricultural land and ecological land are double-edged sword: they absorb carbon dioxide in the atmosphere and emit carbon dioxide into the atmosphere, this paper has calculates carbon uptakes of farmland, garden plot, woodland, grassland and land unused from 2000 to 2012 in Guangdong Province of China with reference to the calculation method by Kuang Yaoqiu et al. (2010), and has calculates net carbon emissions in Guangdong Province based on the amount of energy-related carbon emissions and carbon emissions from soil respiration. The results are shown in Table 4.

Table 4. Estimation results of net carbon emissions in Guangdong from 2000 to 2012.

\begin{tabular}{|c|c|c|c|c|c|c|c|}
\hline \multirow{3}{*}{ year } & \multicolumn{5}{|c|}{ Carbon emissions } & \multirow{3}{*}{$\begin{array}{r}\text { Carbon } \\
\text { uptakes }\end{array}$} & \multirow{3}{*}{$\begin{array}{l}\text { Net carbon } \\
\text { emissions }\end{array}$} \\
\hline & \multicolumn{3}{|c|}{ Energy-related carbon emissions } & \multirow{2}{*}{$\begin{array}{l}\text { Carbon emissions } \\
\text { from soil respiration }\end{array}$} & \multirow{2}{*}{ Total } & & \\
\hline & Total & Productive sector & Household sector & & & & \\
\hline 2000 & 5661 & 5353 & 308 & 5831 & 11,492 & 7140 & 4352 \\
\hline 2001 & 5976 & 5645 & 331 & 5826 & 11,802 & 7133 & 4669 \\
\hline 2002 & 6500 & 6168 & 332 & 5792 & 12,292 & 7100 & 5193 \\
\hline 2003 & 7550 & 7177 & 373 & 5779 & 13,329 & 7086 & 6244 \\
\hline 2004 & 8502 & 8110 & 392 & 5766 & 14,268 & 7072 & 7196 \\
\hline 2005 & 9816 & 9312 & 504 & 5732 & 15,548 & 7037 & 8511 \\
\hline 2006 & 10,847 & 10,325 & 522 & 5701 & 16,548 & 7006 & 9541 \\
\hline 2007 & 12,081 & 11,493 & 588 & 5689 & 17,770 & 6995 & 10,775 \\
\hline 2008 & 12,433 & 11,817 & 616 & 5680 & 18,113 & 6985 & 11,128 \\
\hline 2009 & 13,007 & 12,361 & 646 & 5678 & 18,685 & 6981 & 11,704 \\
\hline 2010 & 13,716 & 13,060 & 656 & 5678 & 19,394 & 6973 & 12,421 \\
\hline 2011 & 15,259 & 14,397 & 862 & 5653 & 20,912 & 6932 & 13,981 \\
\hline 2012 & 15,698 & 14,811 & 887 & 5618.09 & 21,316 & 6915 & 14,401 \\
\hline
\end{tabular}




\subsection{Results of Weighting}

With AHP and entropy method, the weight coefficients of various indicators are shown in Figure 2. During calculating the weight by AHP, With YAAHP's help, 20 experts engaged in environmental, resource and economy studies have been invited to judge the relative importance of the various factors by pairwise comparison method and compose matrix. The results can pass consistency check.

The results show (see Figure 2) that the weight of index Net Export Proportion in GDP $\left(X_{4}\right)$ is the largest, followed by Carbon Emission Density. The weight of $X_{11}$ is minimal. Since the results have a certain scientific basis and conform to the actual situation of Guangdong Province in China, we think we can use them to do further analysis.

\subsection{Results of Evaluation for LCE Development in Guangdong Province}

Based on results of carbon emissions and weighting of indicators and some other data, the results of evaluation for LCE development in Guangdong Province from 2000 to 2012 are shown in Table 5 with composite index method.

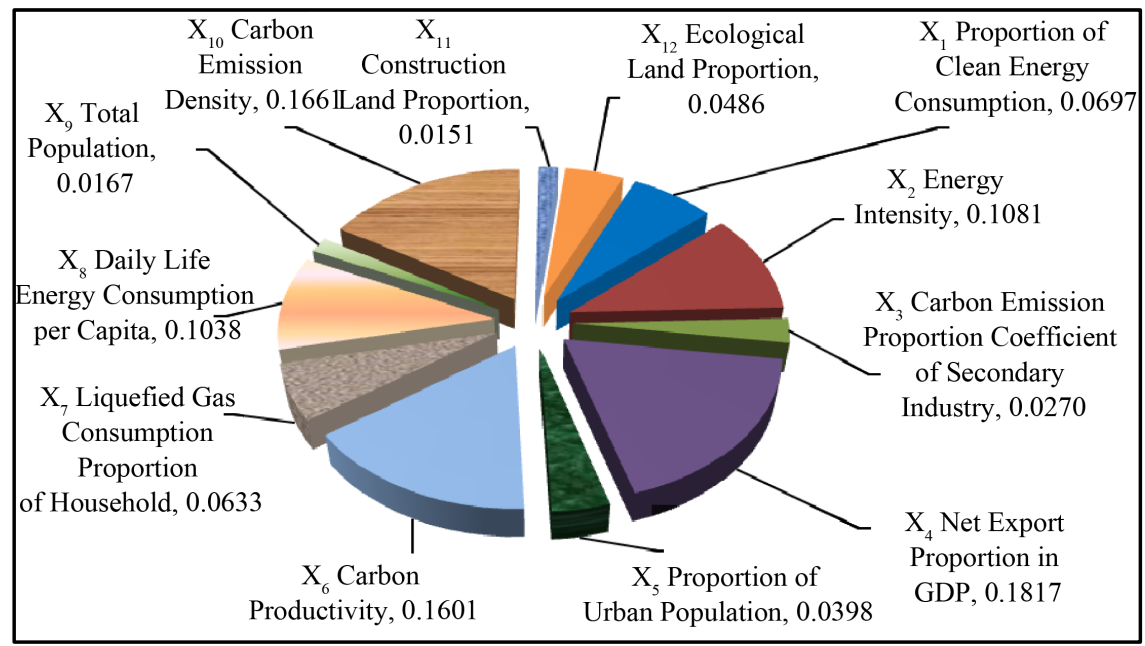

Figure 2. Combination weighting of various indicators.

Table 5. Results of evaluation for LCE development in Guangdong from 2000 to 2012.

\begin{tabular}{ccccc}
\hline Year & Total score & $\begin{array}{c}\text { Factor layer score of } \\
\text { low-carbon production }\end{array}$ & $\begin{array}{c}\text { Factor layer score of } \\
\text { low-carbon life }\end{array}$ & $\begin{array}{c}\text { Factor layer score of low-carbon } \\
\text { environment }\end{array}$ \\
\hline 2000 & 1.2102 & 0.6777 & 0.2400 & 0.2925 \\
2001 & 1.2143 & 0.7093 & 0.2278 & 0.2772 \\
2002 & 1.1981 & 0.7247 & 0.2178 & 0.2556 \\
2003 & 1.1022 & 0.6695 & 0.2090 & 0.2237 \\
2004 & 1.0750 & 0.6682 & 0.2042 & 0.2026 \\
2005 & 0.9242 & 0.5576 & 0.1866 & 0.1800 \\
2006 & 0.8700 & 0.5154 & 0.1882 & 0.1670 \\
2007 & 0.8560 & 0.5202 & 0.1813 & 0.1548 \\
2008 & 0.8690 & 0.5409 & 0.1766 & 0.1513 \\
2009 & 0.9270 & 0.6060 & 0.1747 & 0.1466 \\
2010 & 0.9620 & 0.6377 & 0.1831 & 0.1412 \\
2011 & 0.9160 & 0.6174 & 0.1709 & 0.1273 \\
2012 & 0.9410 & 0.6406 & 0.1756 & 0.1246 \\
\hline
\end{tabular}




\section{Discussion}

\subsection{Discussion on the Estimates of Carbon Emissions}

The estimated results of carbon emissions (see Table 4) show that the total net carbon emissions in Guangdong Province increased from $4352 \times 10^{4} \mathrm{tC}$ (ton of carbon) in 2000 to $14401 \times 10^{4} \mathrm{tC}$ in 2012, and the average annual growth rate is $10.49 \%$. The total net carbon emissions are calculated by subtracting total carbon emissions from total carbon uptakes, so the results lie on the trend of the total carbon emissions and the total carbon uptakes in Guangdong Province. The results show that the total carbon emissions showed increasing trend and the total carbon uptakes showed decreasing trend in Guangdong Province from 2000 to 2012. For carbon emissions, energy-related carbon emissions from productive sector change a lot, increasing from $5353 \times 10^{4}$ tC in 2000 to $14,811 \times 10^{4} \mathrm{tC}$ in 2012 , and the average annual growth rate is $8.85 \%$. This correlates with the rapid economic development in Guangdong Province during period of 2000-2012. So, we can surmise that the rapid economic development lead to large energy-related carbon emissions in Guangdong Province.

\subsection{Comprehensive Evaluation Discussion}

Results (see Table 5) show that overall development of LCE in Guangdong Province was on the decline during the period of 2000-2012. By contrast, Per capita GDP in Guangdong Province during the same period increased steadily year after year (see Figure 3). This shows the rapid increase in Guangdong Province's economy was achieved at the expense of the environment. The trend of LCE level is ascending at first and descending at last in detail (as shown in Figure 3), which can be roughly divided into two stages.

Stage I (2000-2007): The overall development of LCE in this stage showed a downward trend. During this period, the total score in 2001 was highest, 1.2143. The score was declining steadily in other years except in 2000 slightly lower than in 2001, the score in 2007 was lowest, only 0.856 , which decreased by $29.51 \%$ compared with 2001. The key reasons come from two aspects. On one hand, during the period of 2000-2012, three factor layer scores all showed decrease generally. On the other hand, the negative indexes-Net Export Proportion in GDP, Carbon Emission Density and Daily life Energy Consumption per Capita, whose weights are bigshowed an upward trend year by year with very large rangeability, which hindered the development of low carbon economy in Guangdong Province. In addition, the positive index for development of LCE, ecological Land Proportion, showed a downward trend every year, which weakened the ecological carbon absorption effect in Guangdong Province during this period and precluded the development of LEC in Guangdong Province.

Stage II (2008-2012): The overall development of LCE in this stage showed an upward trend with short-term fluctuation in 2011. From 2008 on, the total score of LCE development began to rise year by year with small rangeability, during which the total score in 2011 fluctuated slightly but turned to rise soon in 2012. The reasons are that during 2007-2010, such negative indicators as net export proportion in GDP, energy intensity proportion and liquefied petroleum gas consumption proportion, whose weights are larger, showed a downward trend year

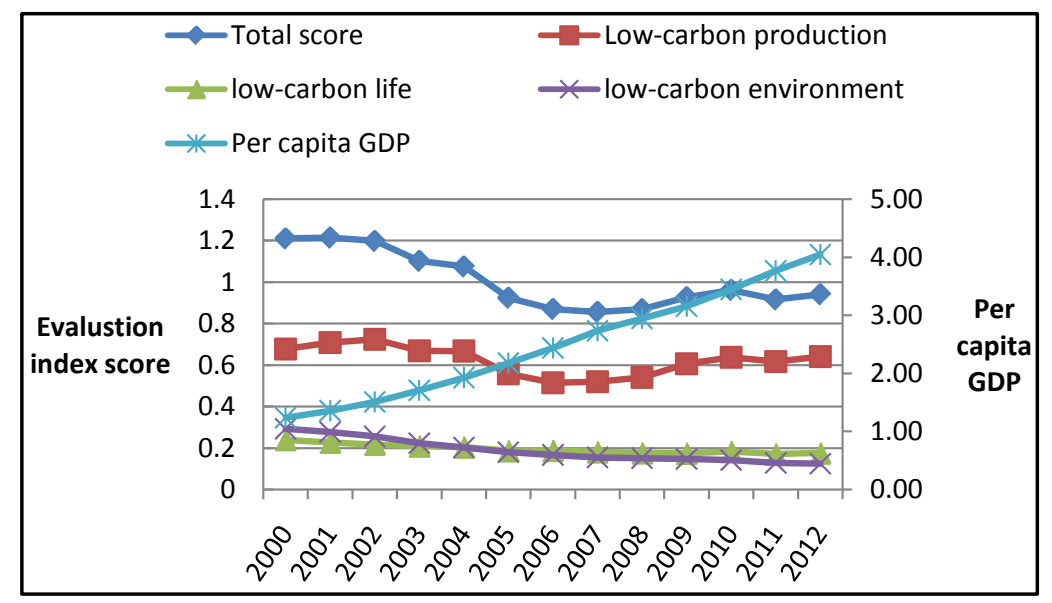

Figure 3. Evaluation trend for LCE and per capita GDP trend in Guangdong from 2000 to 2012. 
by year; while such positive indicators as carbon productivity and clean energy consumption proportion, whose weights are also larger, showed an upward trend year by year. All of this promoted the development of low carbon economy in Guangdong Province during this period. And the score in 2011 declined slightly than in 2010, because from 2010 to 2011, all the twelve positive indicators were on the decline, while all the negative indicators were on the rise except liquefied petroleum gas consumption proportion. The change in the liquefied petroleum gas indicator was so small that the LCE development index in 2011 was smaller than in 2010.

\subsection{Factor Layer Evaluation Discussion}

Judging from factor layer, the scores of low carbon production have the obvious gradual characteristics in Guangdong Province over the years, which can be roughly divided into two stages:

Stage I (2000-2006): The overall development of low carbon production in this stage showed a downward trend in volatility. The reasons lie in the fact that during this period exports in Guangdong Province increased substantially with increasingly distinct export-oriented economic characteristics and the export goods were mostly OEM products with high energy consumption, high pollution and low technology content, which exerted great negative influence on the development of low carbon production. Although other indicators such as carbon productivity, energy intensity, industrial structure and the level of urbanization changed in the favor of the development of low carbon production, but the change was so small that it couldn't counteract the negative influence of the low level of export growth on low carbon economy.

Stage II (2007-2012): Low-carbon production index showed an upward trend year by year. The reasons lie in the fact that proportion of clean energy consumption and carbon productivity were increasing year by year, especially carbon productivity rose substantially, while the negative index such as the energy intensity were decreasing year by year (except 2011). The obvious yearly increase in the scores of low-carbon life index in Guangdong Province showed that the low-carbon life level in Guangdong Province was keeping falling. During the study period, the yearly increase in the indicators representing the urban residents' living standards in Guangdong Province such as disposable personal income and per capita consumption expenditure and the yearly decrease in the Engel coefficient showed that people's living standards in Guangdong Province continued to improve. However, because per capita energy consumption for daily life purpose was increasing year by year and the size of population was constantly expanding, which resulted in a continuous increase in carbon emissions from daily life energy consumption, the low-carbon life level declined rather than increased. The obvious decrease in the scores of low-carbon environment index in Guangdong Province showed that Guangdong's ecological environment was deteriorating year by year, because during this period the proportion of construction land was on the increase and the proportion of ecological land on the decrease, such changes in land use affected the soil organic carbon storage in Guangdong Province and induced the yearly increase in the net carbon emissions in the air.

\section{Conclusions and Policy Implications}

\subsection{Conclusions}

Firstly, the estimated results of net carbon emissions showed an upward trend year by year from 2000 to 2012 and the trend of the energy-related carbon emissions was the main inducement. We can surmise that the rapid economic development brought about huge amount of energy-related carbon emissions in Guangdong Province.

Secondly, this paper has built a LCE quantitative evaluation index system based on the decomposition of the factors influencing carbon emissions from energy consumption and soil respiration under the concept of "life, production and environment”. This index system consists of a target layer (LCE evaluation index system), 3 factor layers (low-carbon production development, low-carbon life promotion and low-carbon environment improvement) and 12 specific indicators, and correlation test verified that there are not significant correlations between different indexes under three factor layers.

Thirdly, by applying AHP and entropy evaluation method to weight each index and using composite index method, this study calculates the scores of LCE composite index, low-carbon production development index, low-carbon life promotion index and low-carbon environment improvement index from 2000 to 2012 in Guangdong Province. Results showed that the low-carbon economy development presented an upward trend after a decline and a downward trend in whole. Judging from factor layer, the scores of low carbon production devel- 
opment index were up after a decline with the obvious gradual characteristics while the scores of low-carbon life promotion index and low-carbon environment improvement index showed a downward trend year by year. Results showed that during the period of 2000-2012 the rapid economic growth in Guangdong Province was achieved at the expense of the environment, during which although low-carbon production development was on the increase after 2007, low-carbon life promotion was on the decline and low-carbon environment could not gain improvement over the same period. The main reasons lie in the present situation in economic development in Guangdong Province. The exports in Guangdong Province increased substantially and the export goods were mostly OEM products with high energy consumption, high pollution and low technology content, which exerted great negative influence on the development of low carbon production. The process of rapid urbanization is also one of the main negative influences. In the process of urbanization, huge amount of energy will be used and the way of land use will be altered, which would increase the net carbon emissions in the air in Guangdong Province.

\subsection{Policy Implications}

The authors believe that there are several effective approaches to improve the development of LCE in Guangdong Province according to the analysis results in Sections 3 and 4. So, the following suggestions are put forward:

1) Paying more attention to the optimization of energy mix from productive sector. The irrational energy structure based on coal, oil and other carbon-rich energy in productive sector in Guangdong Province should not continue. There is great potential to improve the energy mix in the future and a lot of approaches to optimize the energy structure in Guangdong Province. Exploiting new energy sources is an attractive method. So, Guangdong Province should use more clean energy such as solar energy, wind energy, biomass energy, oceanic energy and other new energy resources, and that can become true easily because Guangdong have the most abundant light, heat and water resources in China.

2) Optimizing energy mix from household too. The statistical data show that Guangdong Province is one of the biggest provinces in population in China, and the size of population in Guangdong Province was constantly expanding, which resulted in a continuous increase in carbon emissions from daily life energy consumption. So, it is necessary that Guangdong Province improve the utilization of clean energy in daily life.

3) Attaching equal importance to the structure optimization and its foreign trade scale. As a region that showed distinct export-oriented economic characteristics, the foreign trade scale should be further expanded. However, in the process of that, Guangdong Province should pay more attention to the foreign trade structure optimization. More concretely, it is necessary to use advanced technology to improve production's quality and price and to reduce carbon emissions. In addition, it is certainly worth reducing foundry products with high energy consumption and high pollution. When necessary, Guangdong Province can adjust the structure of trade partner.

4) Taking into account the common development of production, life and environment in land resources planning. Unlike light, heat and water, the land resources in Guangdong Province is very limited. In recent years, the limited construction land have become the important factors which restrict the economic development in Guangdong Province, and it is inevitable to occupy agricultural land or develop unused land to expand the economy, such changes in land use will affect the soil organic carbon storage in Guangdong Province and increase the net carbon emissions in the air. Therefore, it is very necessary to take into account the common development of production, life and environment in land resources planning in Guangdong Province, never seeking for rapid economic growth alone. Only when production, life and environment have realized common development will sustainable economic development come true.

\section{References}

[1] Qin, X.Z. (2010) Evaluation of Enterprise Technology Innovation Project Based on Low-Carbon Economy. Proceedings of the 3rd International Conference on Information Management, Innovation Management and Industrial Engineering (ICIII 2010), Kunming.

[2] Hong, J. and Chen, F.J. (2011) Low Carbon Development Assessment of Fujian Province, China Based on Fuzzy Analytic Hierarchy Process (FAHP) and Forest Carbon Sinks Information. MSIE, 278-281.

[3] Hu, Z.G., Yuan, J.H. and Hu, Z. (2011) Study on China's Low Carbon Development in an Economy-Energy-Electrici- 
ty-Environment Framework. Energy Policy, 39, 2596-2605. http://dx.doi.org/10.1016/i.enpol.2011.02.028

[4] Sustainable Development Strategy Study Group of Chinese Academy of Sciences (2009) China Sustainable Development Report 2009. Science Press, Beijing.

[5] Parikh, J. and Parikh, K. (2011) India’s Energy Needs and Low Carbon Options. Energy, 36, 3650-3658. http://dx.doi.org/10.1016/j.energy.2011.01.046

[6] Li, J.L. (2011) Measurable Indicators of Low-Carbon Economy for Air Transportation-A Case Study of Shenzhen. Energy Procedia, 5, 1697-1705. http://dx.doi.org/10.1016/j.egypro.2011.03.289

[7] He, C. and Feng, X. (2012) Evaluation Indicators for Energy-Chemical Systems with Multi-Feed and Multi-Product. Energy, 43, 344-354. http://dx.doi.org/10.1016/j.energy.2012.04.019

[8] Feng, Z.-M. (2012) The Establishment of Regional Low-Carbon Economic Development Ability Evaluation Index System. Statistics and Decision, 11, 63-65.

[9] Viebahn, P., Daniel, V. and Samuel, H. (2013) Integrated Assessment of Carbon Capture and Storage (CCS) in the German Power Sector and Comparison with the Deployment of Renewable Energies. Applied Energy, 97, $238-248$. http://dx.doi.org/10.1016/j.apenergy.2011.12.053

[10] Subramanian, K.A., Mathad, V.C., Vijay, V.K. and Subbarao, P.M.V. (2013) Comparative Evaluation of Emission and Fuel Economy of an Automotive Spark Ignition Vehicle Fuelled with Methane Enriched Biogas and CNG Using Chassis Dynamometer. Applied Energy, 105, 17-29. http://dx.doi.org/10.1016/j.apenergy.2012.12.011

[11] Yue, T., Long, R.Y., Chen, H. and Zhao, X. (2013) The Optimal $\mathrm{CO}_{2}$ Emissions Reduction Path in Jiangsu Province: An Expanded IPAT Approach. Applied Energy, 112, 1510-1517. http://dx.doi.org/10.1016/j.apenergy.2013.02.046

[12] Eggleston, H.S., Buendia, L., Miwa, K., et al., Eds. (2006) IPCC Guidelines for National Greenhouse Gas Inventories. IGES, Kanagawa.

[13] IPCC (2006) IPCC Guidelines for National Greenhouse Gas Inventories: Volume II. The Institute for Global Environmental Strategies, Japan.

[14] Xiao, H.-J., Kuang, Y.-Q. and Huang, N.-S., et al. (2006) Study on Carbon Budget Change of Guangzhou City under High-Speed Industrial Development. Ecology and Environment, 15, 1209-1215.

[15] Kuang, Y.-Q., Huang, N.-S., Zhu, Z.-Y., et al. (2009) Sustainable Development Process in Guangdong China. Guangdong Science and Technology Press, Guangzhou.

[16] Ye, W.-H. (2009) Establish a Healthy Society with the Common Development of Life, Production and Environment. http://news.xinhuanet.com/video/2011-09/22/c_122075070.htm

[17] Yoichi, K. (1989) Impact of Carbon Dioxide Emission on GNP Growth: Interpretation of Proposed Scenarios. Presentation to the Energy and Industry Subgroup, Response Strategies Working Group, IPCC, Paris.

[18] Wang, Z.H., Yin, F.C., Zhang, Y.X. and Zhang, X. (2012) An Empirical Research on the Influencing Factors of Regional $\mathrm{CO}_{2}$ Emissions: Evidence from Beijing City, China. Applied Energy, 100, 277-284. http://dx.doi.org/10.1016/j.apenergy.2012.05.038

[19] Duarte, R., Mainar, A. and Sánchez-Chóliz, J. (2013) The Role of Consumption Patterns, Demand and Technological Factors on the Recent Evolution of $\mathrm{CO}_{2}$ Emissions in a Group of Advanced Economies. Ecological Economics, 96, 113. http://dx.doi.org/10.1016/j.ecolecon.2013.09.007

[20] Andersson, F.N.G. and Karpestam, P. (2013) $\mathrm{CO}_{2}$ Emissions and Economic Activity: Short- and Long-Run Economic Determinants of Scale, Energy Intensity and Carbon Intensity. Energy Policy, 61, 1285-1294. http://dx.doi.org/10.1016/j.enpol.2013.06.004 
Scientific Research Publishing (SCIRP) is one of the largest Open Access journal publishers. It is currently publishing more than 200 open access, online, peer-reviewed journals covering a wide range of academic disciplines. SCIRP serves the worldwide academic communities and contributes to the progress and application of science with its publication.

Other selected journals from SCIRP are listed as below. Submit your manuscript to us via either submit@scirp.org or Online Submission Portal.
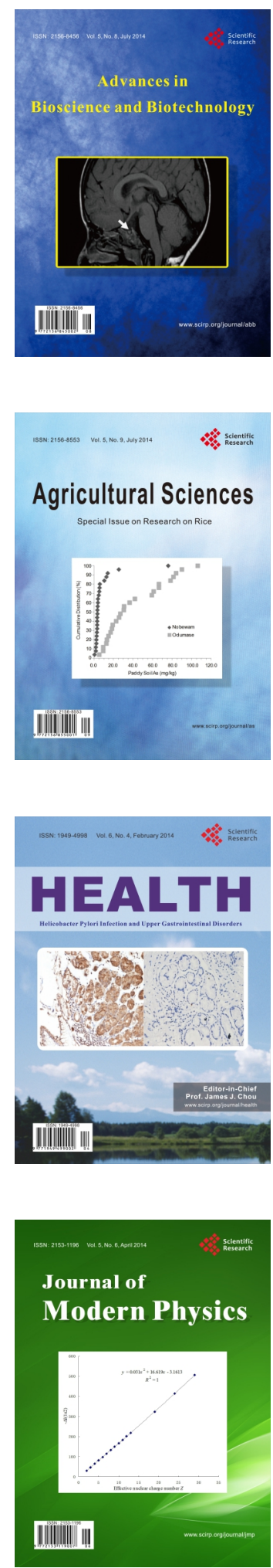
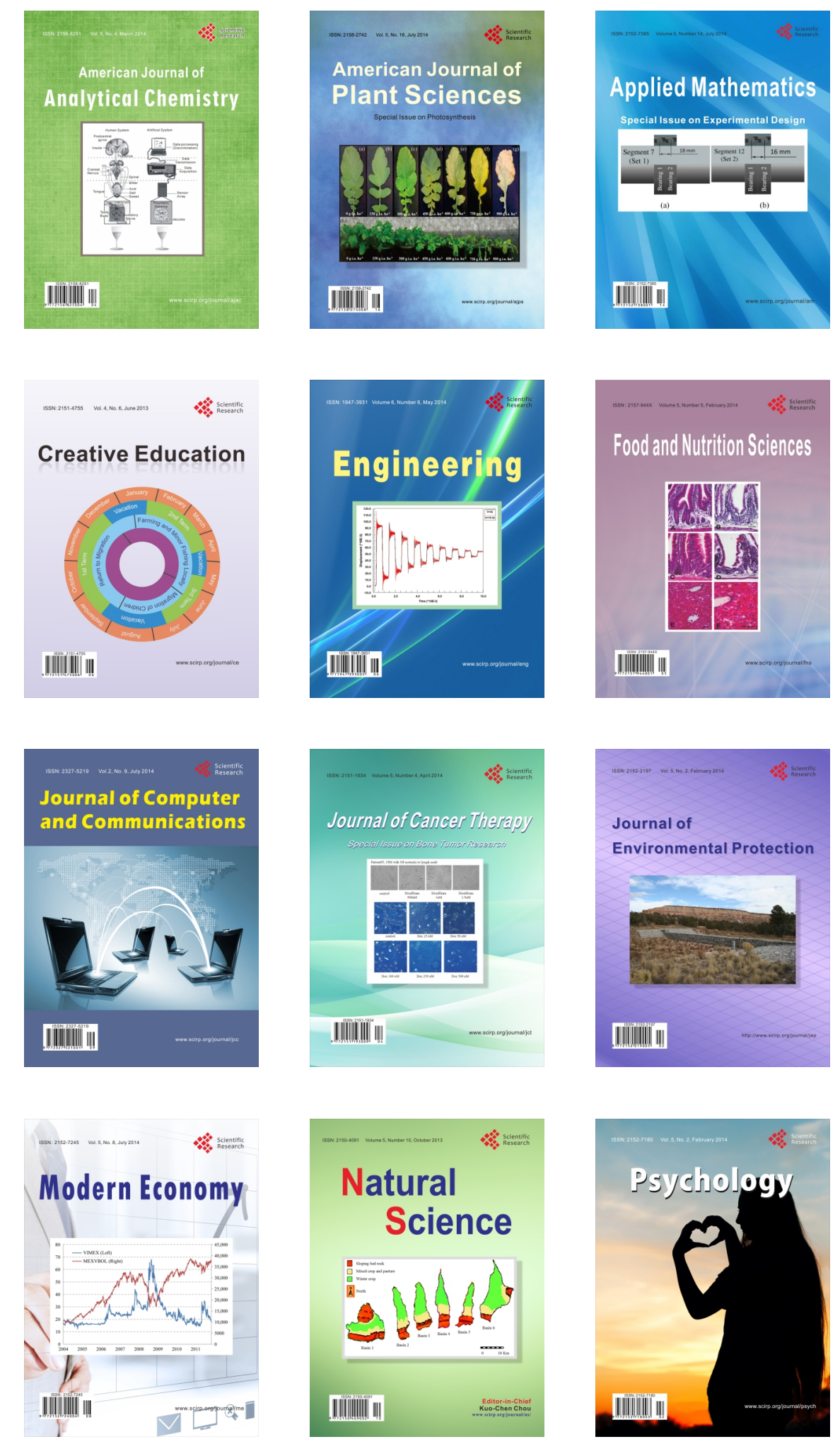